\title{
AVALIAÇÃO AMBIENTAL E ECOLÓGICA DE RIACHOS NEOTROPICAIS DO ALTO RIO PARANÁ
}

Ivaldete Tijolin BARROS ${ }^{1}$

Juliana CECCON-VOLL ${ }^{1}$

Diesse Oliveira SEREIA ${ }^{2}$

Evanilde BENEDITO ${ }^{1,3}$

\begin{abstract}
${ }^{1}$ Centro de Ciências Biológicas, Programa de Pós-Graduação em Biologia Comparada, Universidade Estadual de Maringá, Av. Colombo, 5790, CEP: 87.020-900, Maringá, PR, Brasil.

${ }^{2}$ Universidade Tecnológica Federal do Paraná, Coordenação de Biologia, Estrada Boa Esperança, Km 04, CEP: 85.660000, Dois Vizinhos, PR, Brasil.

${ }^{3}$ Departamento de Biologia, Programa de Pós-Graduação em Ecologia de Ambientes Aquáticos Continentais - PEA, Universidade Estadual de Maringá - Av. Colombo, 5790, CEP: 87.020-900, Maringá, PR, Brasil.
\end{abstract}

\section{Recebido em: 24/07/2016 - Aprovado em: 02/12/2017 - Disponibilizado em: 30/12/2017}

\begin{abstract}
RESUMO
Estudo comparativo entre riachos distintos da bacia do rio Paraná pela aplicação de Protocolo de Avaliação Rápida (PAR). Sendo contemplados nove parâmetros e gradiente de estresse, classificado nas categorias: "ótima" (nota 16 a 20), "boa" (nota 11 a 15), "regular" (nota 6 a 10) e "péssima" (nota 0 a 5), sendo este último o mais alto nível de estresse. O PAR foi aplicado por dois avaliadores e as notas atribuídas a partir da inspeção visual das condições físicas do ambiente, calculou-se a média dos valores de cada parâmetro e a nota final pela somatória dos parâmetros. O PAR revelou que riachos inseridos em Unidades de Conservação apresentam-se melhores preservados. Enquanto que os riachos urbanos apresentaram a pior qualidade dos elementos físicos e estado crítico quanto aos aspectos propostos no PAR. Medidas recomendadas foram: implantação de plano de gestão ambiental para preservação dos recursos hídricos; aplicação do PAR a outros trechos; a utilização dos dados para sensibilização da população regional, considerando ser o PAR uma ferramenta útil para categorizar as condições ambientais de riachos e a qualidade de habitats.

Palavras-chave: Condições ambientais. Unidade de conservação. Avaliação de habitats. Microbacias urbanas.
\end{abstract}

\begin{abstract} environmental conditions of the streams and habitat quality.

\section{INTRODUÇÃO}

As alterações que os ecossistemas aquáticos vêm sofrendo em decorrência do avanço acelerado da urbanização, levam à perda de qualidade e da quantidade de água disponível nos mananciais (ANDREOLI;
\end{abstract}

Comparative study among different streams of the Paraná River basin by applying a Rapid Assessment Protocol (RAP). It is contemplated nine parameters and stress gradient rated in the categories: excellent (score 16-20), good (score 1115), regular (score 6-10) and poor (score 0-5). RAP was applied by two raters and the scores were assigned based on visual inspection of the physical condition of the environment; the value of each parameter was obtained by averaging the values assigned by the raters and the final score by the sum of the parameters. In a gradient, RAP revealed that water bodies within conservation units were better preserved. It's necessary the implementation of an environmental management plan aimed at conserving water resources in the watershed; the application of RAP to other stretches; the use of data to raise awareness in the regional population, considering RAP as a useful tool to categorize the

Keywords: Environmental conditions. Conservation unit. Habitat assessment. Urban microwatersheds.

CARNEIRO, 2005), dificultam a manutenção da integridade desses ecossistemas e interferem na sustentabilidade de suas comunidades (KARR, 1999). A alteração de processos ecológicos e regime fluvial altera significativamente a disponibilidade de 
habitat e a composição trófica no ambiente aquático (RODRIGUES et al., 2010).

A manutenção e a preservação de ecossistemas são necessidades urgentes requeridas pela sociedade moderna, porém ainda são escassos os estudos realizados nesse sentido, especialmente no Brasil. A avaliação da integridade ambiental é o passo inicial para o planejamento e a implementação de programas de preservação e recuperação de habitats

(MINATTI-FERREIRA; BEAUMORD, 2004).

Protocolos para avaliação rápida da integridade ambiental de riachos são amplamente utilizados e permitem a obtenção de dados em curto prazo e com custos reduzidos

(MINATTI-FERREIRA;

BEAUMORD, 2004). Segundo Rodrigues et al. (2010), o entendimento do habitat é importante porque permite compreender os fatores que condicionam a biodiversidade fluvial e contribui para explicar a distribuição e a diversidade biológica dos riachos, entre distintas regiões ecoclimáticas.

A avaliação da qualidade dos habitats físicos por protocolos de avaliação rápida (PARs) é etapa fundamental em programa de biomonitoramento de qualidade da água. Estes parâmetros são avaliados por meio de observações visuais e classificados segundo os atributos dos habitats (CALLISTO; MORENO, 2001), e permitem a proposição de um diagnóstico que contemple características da dinâmica fluvial, como sedimentação e a morfologia dos canais (BIAZIN, 2008), possibilitando o monitoramento qualitativo das condições dos corpos aquáticos (NEWSON; LARGE, 2006). A verificação precoce de pequenas mudanças possibilita impedir a expansão das mesmas a todo ecossistema permitindo que medidas mitigadoras sejam desenvolvidas (RODRIGUES et al., 2010).

O presente estudo utilizou o protocolo proposto por Cionek et al. (2011), fundamentado em características geológicas, geomorfológicas, climáticas, hidrológicas e vegetacionais, e foi adaptado para a região do Arenito Caiuá, noroeste do Paraná -Brasil, que está sob domínio da floresta Estacional Semidecidual, com o intuito de avaliar os aspectos físicos dos habitats de riacho inserido em área de proteção ambiental (Piava APA) e, sem proteção ambiental (Piava CF, Antas, Xambrê e Pinhalzinho) e submetidos a diferentes estados de conservação ambiental.

\section{METODOLOGIA}

O estudo contemplou cinco riachos (Piava APA, Piava CF, Antas, Xambrê e Pinhalzinho) localizadas na bacia do alto rio Paraná (Figura 1).

Figura 1 - Área de estudos e locais de amostragem na bacia do alto rio Paraná. Nota: $\mathbf{O}=$ Piava APA, $\boldsymbol{\square}=$ Piava CF, $\diamond=$ Antas, $\boldsymbol{\Delta}=$ Xambrê, $\boldsymbol{O}=$ Pinhalzinho. 


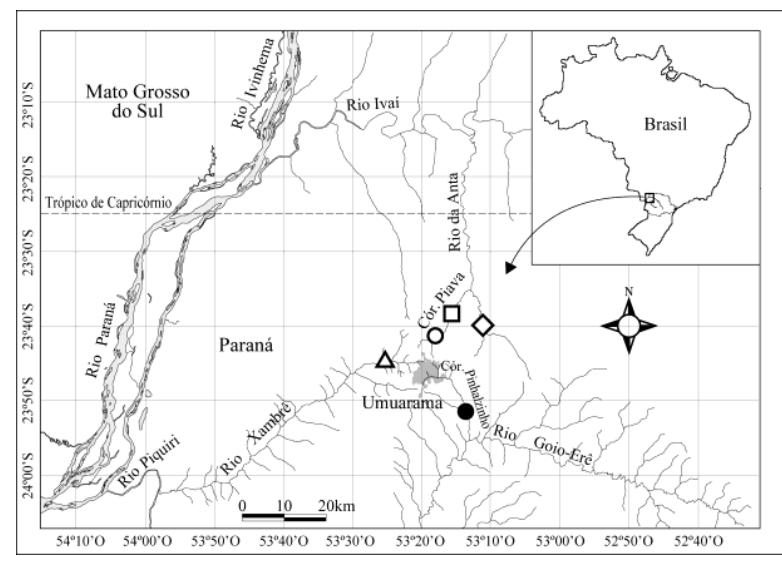

O protocolo contemplou nove parâmetros: substrato de fundo, complexidade do habitat submerso, variação de velocidade e profundidade, sinuosidade do canal, condições de escoamento do canal, alterações no canal, estabilidade dos barrancos, proteção vegetal das margens e estado de conservação da vegetação de entorno. A cada parâmetro foi atribuído um gradiente de estresse, classificado em quatro categorias: "ótima" (nota 16 a 20), "boa" (nota 11 a 15), "regular" (nota 6 a 10) e "péssima" (nota 0 a 5). As notas foram atribuídas a partir da inspeção visual da condição física do ambiente e o valor final do protocolo foi obtido por meio da somatória das notas atribuídas a cada parâmetro, que então, reflete o estado de conservação do trecho analisado (Tabela 1).

Tabela 1 - Amplitude da somatória das notas correspondentes à avaliação das diferentes condições de conservação do trecho do ambiente analisado.

\begin{tabular}{ll}
\hline Condição de Conservação & Notas \\
\hline Ótima & 136 a 180 \\
Boa & 91 a 135 \\
Regular & 46 a 90 \\
Péssima & 0 a 45 \\
\hline
\end{tabular}

Obs.: O protocolo foi aplicado por dois avaliadores.
Para testar a variabilidade entre as médias das notas atribuídas pelos avaliadores para cada trecho, foi aplicado um teste t, realizado no programa Statistica $7.0 \AA$ (STATSOFT, 2005).

\section{RESULTADOS E DISCUSSÃO}

Os resultados obtidos para cada parâmetro a partir da aplicação do protocolo são apresentados na Tabela 2.

Entre os ambientes avaliados apenas o ribeirão Piava APA foi caracterizado como de condição "ótima". Os trechos do Piava CF, Antas e Xambrê foram categorizados como de condição "boa", enquanto do Pinhalzinho como de condição "regular" (Figura 2).

Figura 2 - Resultado correspondente à avaliação dos diferentes parâmetros das condições de conservação dos trechos analisado.

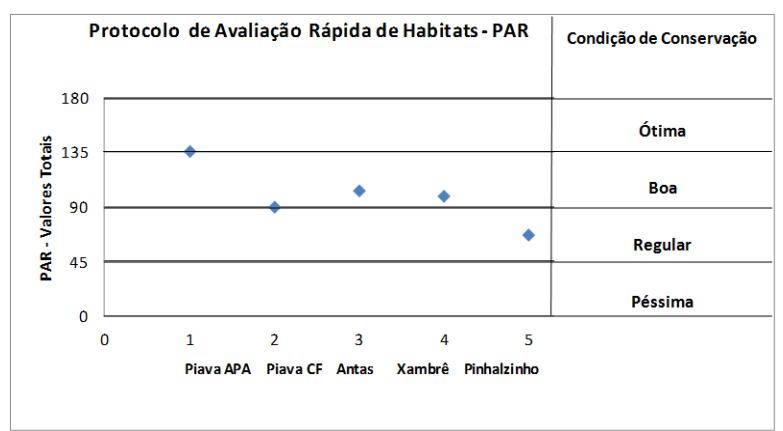

Tabela 2 - Médias das notas atribuídas aos parâmetros propostos pelo PAR na avaliação das diferentes condições de conservação do trecho analisados de cada riacho estudado. 


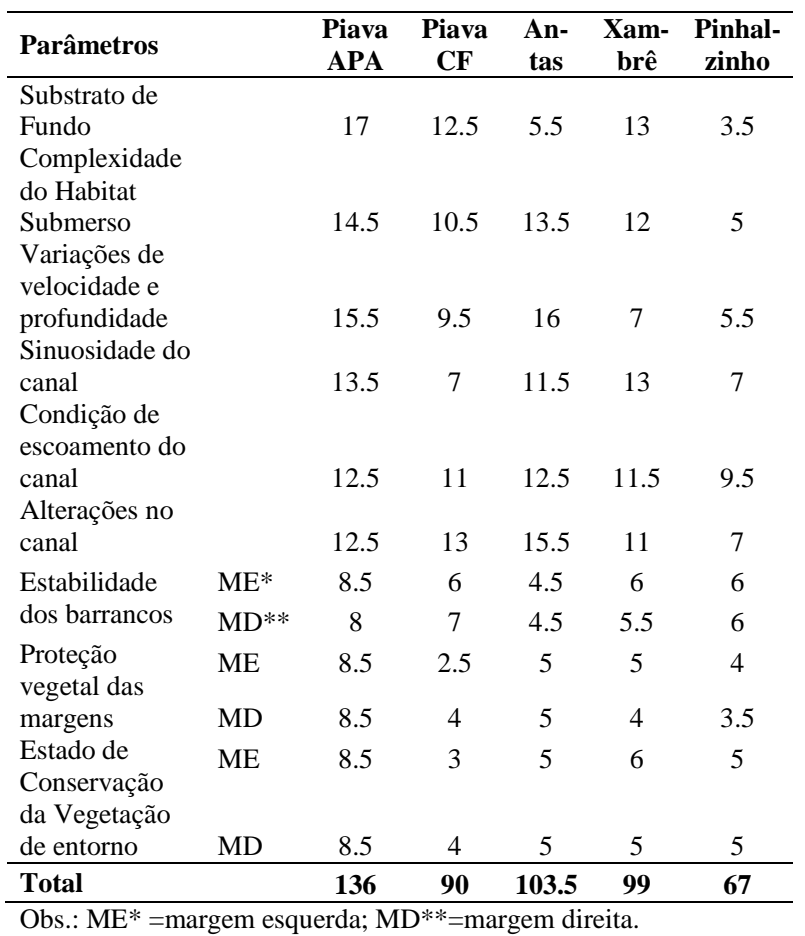

A distinção entre o Piava APA e os demais riachos evidencia a importância da criação de Unidades de Conservação (UC) áreas geográficas destinadas à preservação de ecossistemas naturais. O Piava APA está inserido em uma Área de Proteção Ambiental (APA), que compõe o grupo das Unidades de Conservação de Uso Sustentável, dentro do Sistema Nacional de Unidades de Conservação, do Brasil.

A constatação de melhores condições em substrato de fundo para o Piava APA sinaliza para uma melhor conservação ambiental desse riacho, pois diferentes substratos são fundamentais para a manutenção do ecossistema aquático e de sua biota (FERREIRA; CASATTI, 2006). A maior variedade e/ou proporção de substratos em potencial, disponibilizam diferentes nichos, refúgios, alimentos e locais de desova para peixes, macroinvertebrados bentônicos e perifíton, proporcionando incrementos na diversidade biológica (BARBOUR et al., 1999).

A região do arenito tem como característica o substrato de fundo arenoso, devendo então ser levado em consideração às proporções de areia, cascalhos e seixos, troncos, galhos e folhas caídos na água, bem como a vegetação aquática submersa e a deposição de material orgânico em decomposição (CIONEK et al., 2011). No riacho Piava APA foi possível observar a presença de vários tipos desses substratos fornecedores de habitats em potencial, fato não verificado nos demais riachos $\mathrm{e}$ principalmente no Pinhalzinho.

O fato da região do Arenito Caiuá constituir se em uma das mais críticas do Estado quanto à susceptibilidade à erosão hídrica (EMBRAPA, 1984) pode justificar o resultado obtido para a complexidade do habitat submerso, em que nenhum ambiente estudado alcançou a condição "ótima". A erosão hídrica causa transformações na morfometria dos corpos aquáticos, pelo transporte e carreamento das partículas de areia e cria ambientes mais homogêneos e menos complexos, o que pode restringir comunidades aquáticas (FASOLO et al., 1988). Entretanto, na dinâmica da Floresta Estacional Semidecidual há uma perda de 30 a $50 \%$ das folhas da vegetação no inverno, além da perda de folhas de outros indivíduos 
resistentes a seca ao longo do ano e, essa dinâmica propicia o aporte das folhas, galhos e troncos, oferecendo abrigo biota aquática apta a sobreviver nessas condições (CIONEK et al., 2011).

A ocorrência de diferentes padrões de correnteza e profundidade, observada no Piava APA, pode fornecer condições mais estáveis e propícias à manutenção da biota aquática (Rodrigues et al., 2008), proporcionando habitats em potencial para abrigo, reprodução e alimentação. Barbour et al. (1999) propõe que os cursos de água que apresentam mistura dos padrões: (1) rápido/raso, (2) lento/raso, (3) rápido/profundo e (4) lento/profundo, sejam caracterizados como os de melhores condições. Walters et al. (2003) citam que riachos de pequeno porte, de fundo essencialmente arenoso, sofrem mais acentuadamente os efeitos da correnteza, visto que mudam sua conformação à medida que o fluxo é interrompido ou acentuado, refletindo na composição e distribuição das comunidades aquáticas. Neste contexto, o tamanho do corpo de água é um preditor importante para a compreensão das influências da corrente de água sobre a qualidade do substrato (BARBOUR; STRIBLING, 1991).

$\mathrm{O}$ riacho Pinhalzinho e Piava $\mathrm{CF}$ demonstraram pouca sinuosidade do canal e esse parâmetro é importante na avaliação do meio físico, pois a formação de curvas e meandros nos canais é de suma importância por fornecer proteção ao carreamento de estruturas promotoras de complexidade ambiental, estabilidade de substrato e dos próprios organismos (CIONEK et al., 2011). A absorção de energia pelas curvas protege o curso de água de excessivas erosões e enchentes, e fornece refúgio para a biota durante os eventos de tempestade (GORDON et al., 1992).

As condições de escoamento do canal a partir da inspeção da cobertura de substratos adequados à colonização caracterizada como "regular" no ribeirão Pinhalzinho, evidencia a falta de substratos submersos que tende a impor restrições à sobrevivência e desenvolvimento das comunidades. $\mathrm{O}$ riacho Pinhalzinho recebe lançamento de efluentes de esgotos domésticos e industriais e, sofre grandes flutuações do nível de água em épocas de chuva, devido macrodrenagem urbana, o que tem ocasionado sérios problemas de erosão e assoreamento.

Segundo Callisto et al. (2006), o carreamento de sedimentos tem como consequência o assoreamento de cursos de água. O preenchimento do canal pela água determina as condições de escoamento do curso de água, produzindo locais com mais ou menos substratos expostos e, por conseguinte, determinando a quantidade desses que estão disponíveis para a biota aquática (CIONEK et al., 2011). Quando a água não é suficiente para cobrir o assoalho do rio, as comunidades 
locais são prejudicadas, uma vez que, a quantidade de substratos propícios à sobrevivência dos organismos torna-se limitada (MACDONALD et al., 1991).

Alterações no canal decorrentes de obras para escoamento de drenagem urbana, lançamento de efluentes de esgoto, pontes ou qualquer ação que provoque uma mudança no curso natural da água, como observadas no Xambrê e Pinhalzinho e, podem acarretar prejuízos para as comunidades fluviais (RODRIGUES et al., 2010). A presença das mesmas influencia a seletividade de espécies mais resistentes, dificultando, e até mesmo impedindo, a estabilização e manutenção de um equilíbrio ambiental (ARAÚJO et al., 2009). A biota aquática, em geral, possui requerimentos específicos de habitats, podendo ser sensíveis a pequenas alterações na vazão, ou ainda, a pequenos aumentos na carga sedimentar causado por alterações antropogênicas (HANNAFORD et al., 1999).

O Arenito Caiuá apresenta solos pouco coesos e susceptíveis à erosão, o afloramento de riachos tende a escavar naturalmente o terreno, expondo margens íngremes, com angulação acentuada (CIONEK et al., 2011), razão pela qual todos os riachos foram avaliados entre as condição "regular" e "péssima" quanto a estabilidade dos barrancos. A estabilidade está associada à presença de vegetação enraizada, ou mesmo da serrapilheira, a qual promove a coesão das partículas de areia e diminui os efeitos da erosão (FIGUEIREDO FILHO et al., 2003). Porém, a ausência de vegetação torna os barrancos menos estáveis e mais susceptíveis aos processos erosivos, aumentando as concentrações de sólidos em suspensão no corpo receptor e comprometendo a sobrevivência de espécies mais sensíveis à turbidez

(MINATTI-FERREIRA;

BEAUMORD, 2006).

A condição para a proteção vegetal das margens e estado de conservação da vegetação de entorno entre "regular" e "péssima" observada nos riachos fornece importantes informações sobre esses corpos hídricos, pois uma vegetação bem estruturada e desenvolvida funcionaria como uma barreira física e proporcionaria maior resistência aos processos erosivos, podendo ainda revelar informações sobre a tomada de nutrientes pelas plantas, controle de correnteza de montante e sombreamento da lâmina de água (BARBOUR ; STRIBLING, 1991).

A pontuação total, bem como da maioria dos parâmetros avaliados, separadamente, foi inferior para os riachos Xambrê e Pinhalzinho (Tabela 2). A constatação, no Pinhalzinho, de profundas alterações na estrutura do corpo de água como a ausência de mata ciliar, assoreamento, ausência de variação de velocidade e profundidade do fluxo de água, barrancos instáveis (quedas frequentes), alterações no canal para a drenagem urbana e ausência de diversidade de habitats, foram os principais 
responsáveis pelos baixos valores dos parâmetros analisados. Chama a atenção, também, à situação do entorno desses riachos por apresentarem nascentes urbanas, consequentemente, condições de maior comprometimento ambiental, sendo que no Pinhalzinho estas condições são mais evidentes. Entretanto, a interferência da urbanização, ou o progresso urbano e civilizatório não devem ser usados como pretexto para a degradação ambiental desenfreada de ecossistemas (KRUPEK, 2010).

Assim, constatou-se a necessidade de desenvolvimento de estudos mais pormenorizados nesses riachos, procurando detectar as regiões mais fragilizadas, com a finalidade de desenvolver planos de manejo integrados que visem à recuperação desses ambientes.

Os riachos Piava CF, Antas e Xambrê apresentaram-se em condições "boas". Entretanto, encontram-se áreas menos preservadas ao longo do curso de água, com sinais de influência antrópica como alterações urbanas, uso intensivo de agricultura e pecuária, ausência de mata ciliar, erosão nas suas margens, assoreamento e trechos altamente degradados. Segundo Callisto et al. (2002), os múltiplos impactos humanos têm sido responsáveis pela deterioração da qualidade ambiental, na maioria das bacias hidrográficas brasileiras.
O protocolo de avaliação rápida permitiu indicar pequenas alterações nos atributos físicos dos habitats dos riachos neotropicais, mostrando que corpos aquáticos inseridos em Unidades de Conservação, apresentam-se mais preservados, evidenciado melhores condições ambientais no Piava APA.

\section{REFERÊNCIAS}

ANDREASEN, J. K.; O’NEILL, R. V.; NOSS, R.; SLOSSER, N.C. Considerations for the development of a terrestrial index of ecological integrity. Ecological Indicators, n.1, p. 21-35, 2001.

ANDREOLI, C. V.; CARNEIRO, C. Gestão integrada de mananciais de abastecimento eutrofizados. Curitiba, Sanepar-Finep, 2005, $500 \mathrm{p}$.

ARAÚJO, F. G.; PEIXOTO, M. G.; PINTO, B. C. T.; TEIXEIRA, T. P. Distribution of guppies Poecilia reticulata (Peters, 1860) and Phalloceros caudimaculatus (Hensel, 1868) along a polluted stretch of the Paraíba do Sul River, Brazil. Brazilian Journal of Biology, n. 69, p. 41-48, 2009.

BARBOUR, M. T.; STRIBLING, J. B. Use of habitat assessment in evaluating the biological integrity of stream communities. In: George Gibson, editor. Biological criteria: Research and regulation, proceedings of a symposium, 12-13 December 1990, Arlington, Virginia. Office of Water, U.S. Environmental Protection Agency, Washington, D.C. EPA440-5-91-005, 1991.

BARBOUR, M. T.; GERRITSEN, J.; SNYDER, B. D.; STRIBLING, J. B. Rapid Bioassessment Protocols for Use in Streams and Wadeable Rivers: Periphyton, Benthic Macroinvertebrates and Fish. 2nd Ed. U.S. Environmental Protection Agency Washington, D.C. EPA 841-B-99-002, 1999. 
BIAZIN, P. C. Característica geomorfológica do canal e das formas de leito do rio Ivaí em seu curso inferior, Icaraíma - PR. Revista Brasileira de Geomorfologia, n. 9, p. 43-52, 2008.

CALLISTO, M.; MORENO, P.; BARBOSA, F. Habitat diversity and benthic functional trophic groups at Serra do Cipó, Southeast Brazil. Revista Brasileira de Biologia, n.61, p. 259-266, 2001.

CIONEK, V. M.; BEAUMORD, A. C.; BENEDITO, E. Protocolo de Avaliação Rápida de Ambiente para riachos inseridos na região do Arenito Caiuá - Noroeste do Paraná. Maringá, Eduem, 2011, 47 p.

EMBRAPA. Serviço Nacional de Levantamento e Conservação de Solos, Levantamento de reconhecimento dos solos do Estado do Paraná. Londrina, Embrapa SNLCS, 1984, 791 p.

FASOLO, P. J.; CARDOSO, A. P.; HOCHMÜLLER, D. P.: RAUEN, M. J.; PÖTTER, R. O. Erosão: Inventário de áreas críticas no Noroeste do Paraná. Londrina, IAPAR, 1988, $20 \mathrm{p}$.

FERREIRA, C. P.; CASATTI, L. Influência da estrutura do habitat sobre a ictiofauna de um riacho em uma microbacia de pastagem, São Paulo, Brasil. Revista Brasileira de Zoologia, n. 23, p. 642-651, 2006.

FIGUEIREDO FILHO, A.; MORAES, G. F.; SCHAAF, L. B.; FIGUEIREDO, D. J. Avaliação estacional da deposição de serrapilheira em uma floresta ombrófila mista localizada no sul do Estado do Paraná. Ciência Florestal, n.13, p. 11-18, 2003.

GORDON, N. D.; MCMAHON, T. A.; FINLAYSON, B. L. Stream hydrology: an introduction for ecologists. West Sussex, John Wiley and Sons, 1992, 526 p.

HANNAFORD, M. J.; BARBOUR, M. T.; RESH, V. H. Training reduces observer variability in visual-based assessments of stream habitat. Journal of the North
American Benthological Society, n. 16, p. 853-860, 1997.

KARR, J.; CHU, E. W. Restoring life in running waters: better biological monitoring. Washington, Inland Press, 1999, 206 p.

KRUPEK, R. A. Análise comparativa entre duas bacias hidrográficas utilizando um protocolo de avaliação rápida da diversidade de habitats. Ambiência, n. 6, p. 147-158, 2010.

MACDONALD, L. H.; SMART, A. W.; WISSMAR, R. C. Monitoring guidelines to evaluate effects of forestry activities on streams in the Pacific Northwest and Alaska. Washington, EPA, 1991, 180 p.

MINATTI-FERREIRA, D. D.; BEAUMORD, A. C. Avaliação rápida de integridade ambiental das sub-bacias do rio Itajaí-Mirim no município de Brusque, SC. Revista Saúde Ambiente, n. 5, p. 21-27, 2004.

NEWSON, M. D.; LARGE, A. R. L. 'Natural' rivers, 'hydromorphological quality' and river restoration: A challenging new agenda for applied fluvial geomorphology. Earth Surface Processes Landforms, n. 31, p. 1606-1624, 2006.

RODRIGUES, A. S. L.; MALAFAIA, G.; CASTRO, P. T. A. A importância da avaliação do habitat no monitoramento da qualidade dos recursos hídricos: uma revisão. SaBios - Revista de Saúde e Biologia, n. 5, p. 26-42, 2010.

STATSOFT INC. Statistica for Windows (data analysis softwaaare system), version 7.0. Tulsa, StatSoft, 2005.

WALTERS, D. M.; LEIGH, D. S.; FREEMAN, M. C.; FREEMAN, B. J.; PRINGLE, C. M. Geomorphology and fish assemblages in a Piedmont river basin, USA. Freshwater Biology, n. 48, p. 1950-1970, 2003. 